\title{
Recent climate variation in the Bering and Chukchi Seas and its linkages to large-scale circulation in the Pacific
}

\author{
Sae-Rim Yeo • Kwang-Yul Kim • Sang-Wook Yeh • \\ Baek-Min Kim • Taehyoun Shim · Jong-Ghap Jhun
}

Received: 23 December 2012/Accepted: 26 December 2013/Published online: 5 January 2014

(C) The Author(s) 2014. This article is published with open access at Springerlink.com

\begin{abstract}
The thermal state of the Bering Sea exhibits interdecadal variations, with distinct changes occurred in 1997-1998. After the unusual thermal condition of the Bering Sea in 1997-1998, we found that the recent climate variability (1999-2010) in the Bering Sea is closely related to Pacific basin-scale atmospheric and oceanic circulation patterns. Specifically, warming in the Bering and Chukchi Seas in this period involves sea ice reduction and stronger oceanic heat flux to the atmosphere in winter. The atmospheric response to the recent warming in the Bering and Chukchi Seas resembles the North Pacific Oscillation (NPO) pattern. Further analysis reveals that the recent climate variability in the Bering and Chukchi Seas has strong covariability with large-scale climate modes in the Pacific, that is, the North Pacific Gyre Oscillation and the central Pacific El Niño. In this study, physical connections among the recent climate variations in the Bering and Chukchi Seas, the NPO pattern and the Pacific large-scale climate patterns are investigated via cyclostationary empirical orthogonal function analysis. An additional model
\end{abstract}

S.-R. Yeo · K.-Y. Kim $(\bowtie) \cdot$ T. Shim · J.-G. Jhun

School of Earth and Environmental Sciences, Seoul National

University, Seoul 151-747, Republic of Korea

e-mail: kwang56@snu.ac.kr

S.-W. Yeh

Department of Environmental Marine Science,

Hanyang University, Ansan 426-792, Republic of Korea

B.-M. Kim · T. Shim

Korea Polar Research Institute, Incheon 406-840,

Republic of Korea

J.-G. Jhun

Research Institute of Oceanography, Seoul National University, Seoul 151-747, Republic of Korea experiment using the National Center for Atmospheric Research Community Atmospheric Model, version 3, is conducted to support the robustness of the results.

Keywords Bering and Chukchi Seas · North Pacific Oscillation · North Pacific Gyre Oscillation · Central Pacific El Niño

\section{Introduction}

The Bering Sea, a northern extension of the North Pacific Ocean, is located between Russia and Alaska and is the third largest semi-enclosed sea in the world. The Bering Sea is connected to the Chukchi Sea, which is a marginal sea of the Arctic Ocean, through the Bering Strait. In a global sense, the Bering Sea acts as the Pacific gateway, through which the North Pacific and the Arctic Ocean exchange heat and water. The Bering Sea is one of the most productive marine resources in the world and provides nearly half of the US fisheries production (National Research Council 1996). For this reason, many oceanographers have tried to understand the variability of the marine ecosystem in the Bering Sea. In particular, its relationship with climate variability has long been the focus of attention (Grebmeier et al. 2006; Overland and Stabeno 2004; Hunt et al. 2002; Kruse 1998; Brodeur et al. 1999). Furthermore, the Bering Sea, as a marginal section of the North Pacific Ocean, is sensitive to Pacific largescale climate phenomena such as the El Niño/Southern Oscillation (ENSO) (Niebauer 1988) and the Pacific Decadal Oscillation (PDO) (Hare and Mantua 2000; Overland et al. 1999). Understanding the oceanic and atmospheric variability over the Bering Sea, therefore, is essential from both ecological and climatological perspectives. 
Atmospheric and oceanic parameters in the Bering Sea vary over a wide range of time scales, from interannual to multi-decadal scales, including trends or climate regime shifts. In particular, recent studies have noted that noteworthy changes in the Bering Sea have occurred recently. For example, the Bering Sea experienced marked warming and a reduction in sea ice during the last decade (Grebmeier et al. 2006; Hunt et al. 2002; Overland and Stabeno 2004; Stabeno et al. 2007). In particular, the striking warming events were concentrated in the years 2000-2005 (Overland et al. 2012). Prominent anomalies in atmospheric and oceanic conditions in the Bering Sea occurred during 1997 and 1998. The sea surface temperature (SST) in the Bering Sea increased up to $5-6{ }^{\circ} \mathrm{C}$ above the average for August and September in 1997, and SST continued to be approximately $2{ }^{\circ} \mathrm{C}$ higher than average through the summer of 1998. The biological conditions were also anomalous, including major cocolithophorid blooms, salmon returns far below predicted numbers, and the unusual presence of whales over the middle shelf (Hunt et al. 1999; Kruse 1998; Minobe 2002; Napp and Hunt 2001; Schumacher et al. 2003; Stabeno et al. 2001; Stockwell et al. 2001). It is likely that these changes in the Bering Sea are closely related to the state of the North Pacific climate system. Moreover, Minobe (2002) argued that the changes in the Bering Sea in the late-1990s are a part of the Pacificscale atmospheric and oceanic change, which is regarded as a potential climatic regime shift. The linkage between the Bering Sea and the North Pacific large-scale climate variability was supposed to be established primarily through the atmosphere; in particular, the connection between the two regions seems to vary according to the strength and position of the Aleutian Low (Niebauer 1988; Overland et al. 1999; Stabeno et al. 2001).

Meanwhile, the large-scale climate variability in the North Pacific also seems to have undergone a significant change during the last decade. According to recent studies, the amplitude of North Pacific Gyre Oscillation (NPGO), which is characterized by a dipole-like SST pattern in the North Pacific became larger than the PDO amplitude during the recent decade (Bond et al. 2003; Di Lorenzo et al. 2008; Yeh et al. 2011). The NPGO appears to be driven by the atmospheric North Pacific Oscillation (NPO) (Rogers 1981), which is the second dominant mode of sea level pressure variability in the North Pacific (Ceballos et al. 2009; Di Lorenzo et al. 2010; Furtado et al. 2011). The NPO pattern consists of a meridional dipole in sea level pressure, with centers of action on both sides of approximately $50^{\circ} \mathrm{N}$.

As noted above, the climate in the Bering Sea and the North Pacific seems to have experienced remarkable changes in the recent decade. It is necessary to contemplate whether the changes in different parts of the Pacific are physically and dynamically linked with each other or not. In this study, therefore, we sought to identify the pattern of the North Pacific variability that is associated with the major physical changes in the Bering Sea, focusing particularly on the recent decade. Our analysis substantiates that the Bering Sea oceanic variability from 1999 to 2010 (i.e., after the unusual conditions in 1997/1998) has a profound impact on atmospheric circulation in the North Pacific, which is characterized by the NPO-like pattern in winter. The accompanying oceanic circulation pattern in the North Pacific features the NPGO pattern, as expected. Furthermore, our analysis found that the recent warming in the Bering Sea had significant covariability with warming in the tropical central Pacific, that is central Pacific (CP) El Niño, which is clearly distinguishable from the canonical eastern Pacific (EP) El Niño (Ashok et al. 2007; Kao and Yu 2009; Kug et al. 2009; Lee and McPhaden 2010; Yeh et al. 2009).

The major analysis tools in the present study are the cyclostationary empirical orthogonal function (CSEOF) method and the regression analysis in CSEOF space. Additional model simulations using NCAR Community Atmospheric Model, version 3 (CAM3), were conducted to test the robustness of the result. The details of the analysis methods are presented in Sect. 2 along with a brief description of the data used in this study. In Sect. 3, recent change in the relationship between the Bering Sea and the North Pacific variability is investigated via CSEOF analysis. Then, the detailed physical conditions over the Bering Sea associated with the warming in 1999-2010 are identified in Sect. 4. The corresponding atmospheric conditions over the North Pacific are described in Sect. 5. Section 6 depicts the large-scale circulation patterns in the Pacific basin associated with the recent Bering Sea warming. Discussion and concluding remarks of this study follow in the last section.

\section{Data and methods}

\subsection{Data}

Monthly mean oceanic and atmospheric datasets for the 31-year period from 1980 to 2010 were used in the present study. The monthly mean SST data were obtained from the Extended Reconstruction SST, version 3 (ERSST. v3) (Smith et al. 2008). The monthly mean sea ice concentration (SIC) data were acquired from the Hadley Centre sea ice and SST dataset, version 1 (HadISST1) (Rayner et al. 2003), which is archived at the UK Meteorological Office. The atmospheric data including geopotential heights, zonal and meridional winds, air temperatures and net surface energy fluxes (latent heat, sensible heat, and shortwave and 
longwave radiative fluxes) were taken from the NCEP/ DOE AMIP-2 reanalysis (Kanamitsu et al. 2002).

\subsection{Methods}

CSEOF analysis (Kim and North 1997; Kim et al. 1996) is applied to the monthly atmospheric and oceanic datasets. Physically evolving spatial patterns are extracted from space-time data, $T(r, t)$, through CSEOF analysis:

$T(r, t)=\sum_{n} L V_{n}(r, t) P C_{n}(t)$

where $L V_{n}(r, t)$ is CSEOF loading vector, $P C_{n}(t)$ is the corresponding principal component (PC) time series, and $n$, $r$ and $t$ denote the mode number, space and time, respectively. The CSEOF method is useful for describing temporally evolving spatial patterns because the CSEOF loading vectors, $L V_{n}(r, t)$, are time dependent and periodic:

$L V_{n}(r, t)=L V_{n}(r, t+d)$

where $d$ is called the nested period. In this study, the nested period is set to 12 months implying that the statistical properties of each physical process do not vary from 1 year to another. Thus, the physical evolution as represented by $L V_{n}(r, t)$ is modulated over a longer time span by the PC time series, $P C_{n}(t)$.

After CSEOF analysis is conducted on individual variables, regression analysis is performed in CSEOF space to find physically consistent patterns among different variables. The PC time series of a predictor variable, $P C P_{m}(t)$, is regressed onto the $\mathrm{PC}$ time series of the target variable, $P C_{n}(t)$, as in (3):

$P C_{n}(t)=\sum_{m=1}^{M} a_{m}^{(n)} P C P_{m}(t)+\varepsilon^{(n)}(t)$

where $\alpha_{m}^{(n)}$ and $\varepsilon^{(n)}(t)$ are regression coefficients and regression error time series, respectively. The regression coefficients are determined such that the variance of the regression error time series is minimized. Then, new loading vectors for the predictor variable, $\operatorname{LVPR}_{n}(r, t)$, are obtained as

$\operatorname{LVPR}_{n}(r, t)=\sum_{m=1}^{M} a_{m}^{(n)} L V P_{m}(r, t)$

where $L V P_{m}(r, t)$ are the CSEOF loading vectors for the predictor variable. The resulting regressed spatial patterns of the predictor variables are considered physically and dynamically consistent with the target patterns in that the two loading vectors share the same amplitude time series $T_{n}(t)$. In the present study, SST in the Bering Sea is selected as the target variable whereas other variables such as SST and atmospheric variables in the Pacific basin are regarded as the predictor variables.

\section{CSEOF LVs (Bering/Chukchi)}
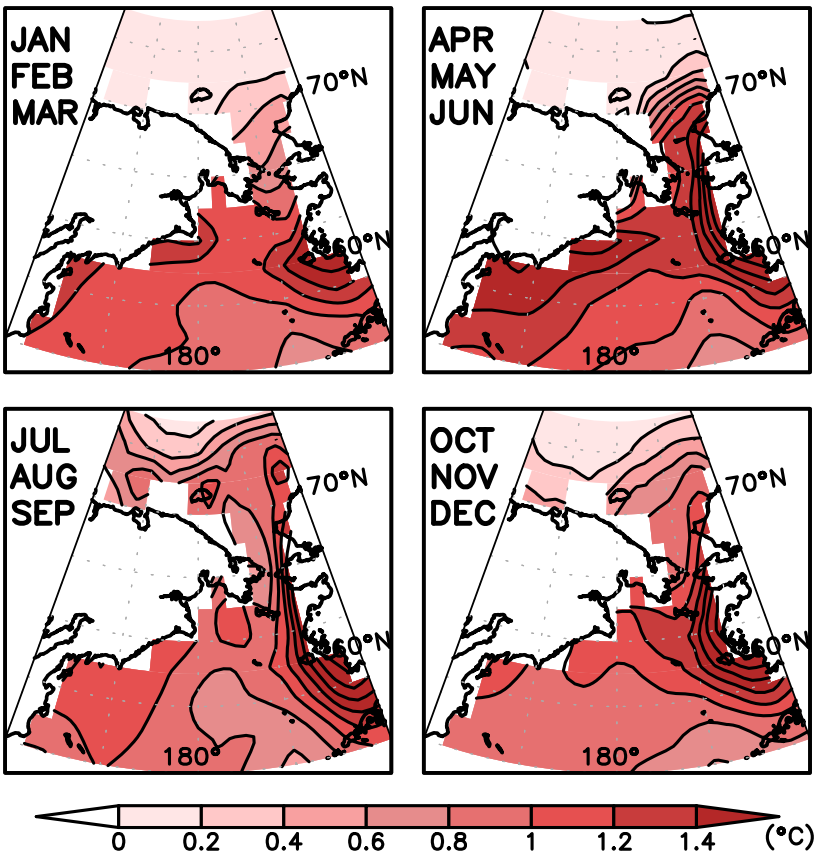

Fig. 1 The first CSEOF loading vectors of the 31-year (1980-2010) monthly SSTA $\left({ }^{\circ} \mathrm{C}\right)$ in the Bering and Chukchi Seas $\left(160^{\circ} \mathrm{E}-160^{\circ} \mathrm{W}\right.$, $\left.54^{\circ}-76^{\circ} \mathrm{N}\right)$. The contour interval is $0.2^{\circ} \mathrm{C}$. Each spatial pattern represents the seasonal (3-month) average of the loading vectors

Model experiments are conducted using $\mathrm{CAM} 3$, an atmospheric general circulation model developed by the National Center for Atmospheric Research (NCAR), to further assess the atmospheric response over the North Pacific to the changed physical conditions in the Bering and Chukchi Seas in recent decade. The physical and numerical methods used in CAM3 are documented in Collins et al. (2006) and the references therein.

\section{Changes in the relationship between the Bering Sea and the North Pacific}

Figure 1 illustrates the first CSEOF loading vector for the SST anomaly (SSTA) over the Bering and Chukchi Seas $\left(160^{\circ} \mathrm{E}-160^{\circ} \mathrm{W}, 54^{\circ}-76^{\circ} \mathrm{N}\right)$ during the 31 -year period of 1980-2010, which explains approximately $31 \%$ of the total variance in SSTA in this region. Because the spatial patterns show a positive SSTA throughout the whole year, the seasonal (3-month) mean CSEOF loading patterns are presented in Fig. 1. The corresponding PC time series, presented as a black bar in Fig. 2, exhibits a weak warming trend from 1980 to 1997, with the warmest year in 1997 followed by a sharp cooling until 1998. This result agrees with previous studies, which documented extreme anomalous conditions in the Bering Sea during 1997 and 1998; 
Fig. 2 The CSEOF PC time series of the Bering and Chukchi SST anomaly (black bar, corresponding to the loading vectors in Fig. 1) and North Pacific SST anomaly (blue line, corresponding to the loading vector in Fig. 3). The vertical dashed line indicates the year 1999

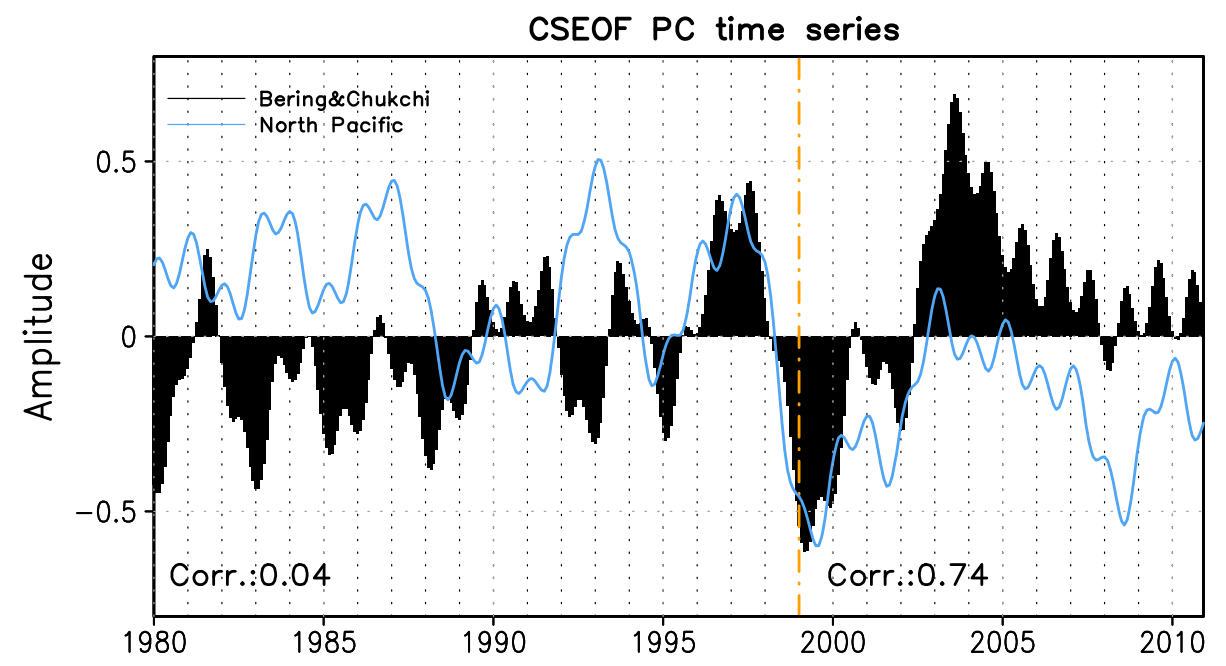

the warmest temperature ever observed before appeared in 1997, which is followed by rapid cooling until 1999 (Hunt et al. 1999; Kruse 1998; Minobe 2002; Napp and Hunt 2001; Schumacher et al. 2003; Stabeno et al. 2001; Stockwell et al. 2001). After an abrupt decline from 1998 to 1999 , SST displayed a sharp increase from 1999 to 2003 and the summer of 2003 marked the warmest year in the entire record (1980-2010). This result is consistent with the recent studies suggesting warming in the Bering Sea in the early 2000s (Grebmeier et al. 2006; Hunt et al. 2002; Overland and Stabeno 2004; Overland et al. 2012; Stabeno et al. 2007). Although there is no warming trend since 2003, SST over the Bering Sea has been warmer during 2003-2010 compared with the mean SST in 1980-2010.

To identify any links between the Bering and Chukchi Seas and climate variability in the North Pacific, North Pacific $\left(100^{\circ} \mathrm{E}-80^{\circ} \mathrm{W}, 20^{\circ}-80^{\circ} \mathrm{N}\right)$ SSTA data were analyzed via CSEOF analysis. The seasonally (3-month) averaged loading vector of the first CSEOF is presented in Fig. 3; the first mode explains approximately $23 \%$ of the total variability. The corresponding PC time series is shown in Fig. 2 as a blue curve. The spatial patterns in Fig. 3 are similar to the structure of the PDO, which features negative SSTA with an elliptical shape over the western to central Pacific and positive SSTA along the eastern North Pacific. Correlation between the first PC time series of the North Pacific SSTA and the Mantua's PDO index (available at http://jisao.washington.edu/pdo/PDO. latest) is 0.73 confirming the similarity between the first CSEOF (Fig. 3) and the PDO patterns. On the other hand, the strong meridional gradient of SSTA along approximately $40^{\circ} \mathrm{N}$ in Fig. 3 is more in line with the structure of the NPGO than the PDO. Indeed, the NPGO index (available at http://www.o3d.org/npgo) and the first PC time series of the North Pacific SSTA are also significantly correlated at -0.63 . In terms of the spatial pattern and the amplitude time series, the first CSEOF loading vector of the North Pacific SSTA (Fig. 3) reflects both the PDO and the NPGO features.

The PC time series of the first CSEOF of the SSTA in the Bering and Chukchi Seas (black bar) and that of the North Pacific (blue line) are presented in Fig. 2. One notable feature in Fig. 2 is the remarkable difference in the relationship between the two PC time series before and after 1999. The two PC time series are significantly correlated ( $r=0.74$ ) with each other in 1999-2010, but the correlation is obscure $(r=0.04)$ in 1980-1998. This result implies that the link between the Bering and Chukchi Seas and the North Pacific SST variability during the recent decade (1999-2010) is clearly distinguishable from that in the previous period (1980-1998). The Bering Sea appears to be more closely connected to the North Pacific in terms of SST variations after it experienced the unusual physical conditions during 1997-1998.

\section{Atmospheric and oceanic variability in the Bering Sea during 1999-2010}

Before the linkage between the Bering Sea and the North Pacific from 1999 to 2010 could be clarified, the variability of the physical environment over the Bering Sea during this period needed to be analyzed. Figure 4 shows the seasonal (3-month) mean patterns of the first CSEOF loading vector for the Bering and Chukchi SSTA from 1999 to 2010; the first mode explains approximately $38 \%$ of the total variability. The first CSEOF loading vector for the Bering and Chukchi SSTA from 1999 to 2010 is similar to that of the entire record (1980-2010) in Fig. 1, both showing a positive SSTA throughout the year. In particular, Fig. 4 displays large anomalies over the shallow shelf in the eastern Bering Sea. The corresponding PC time series exhibits 


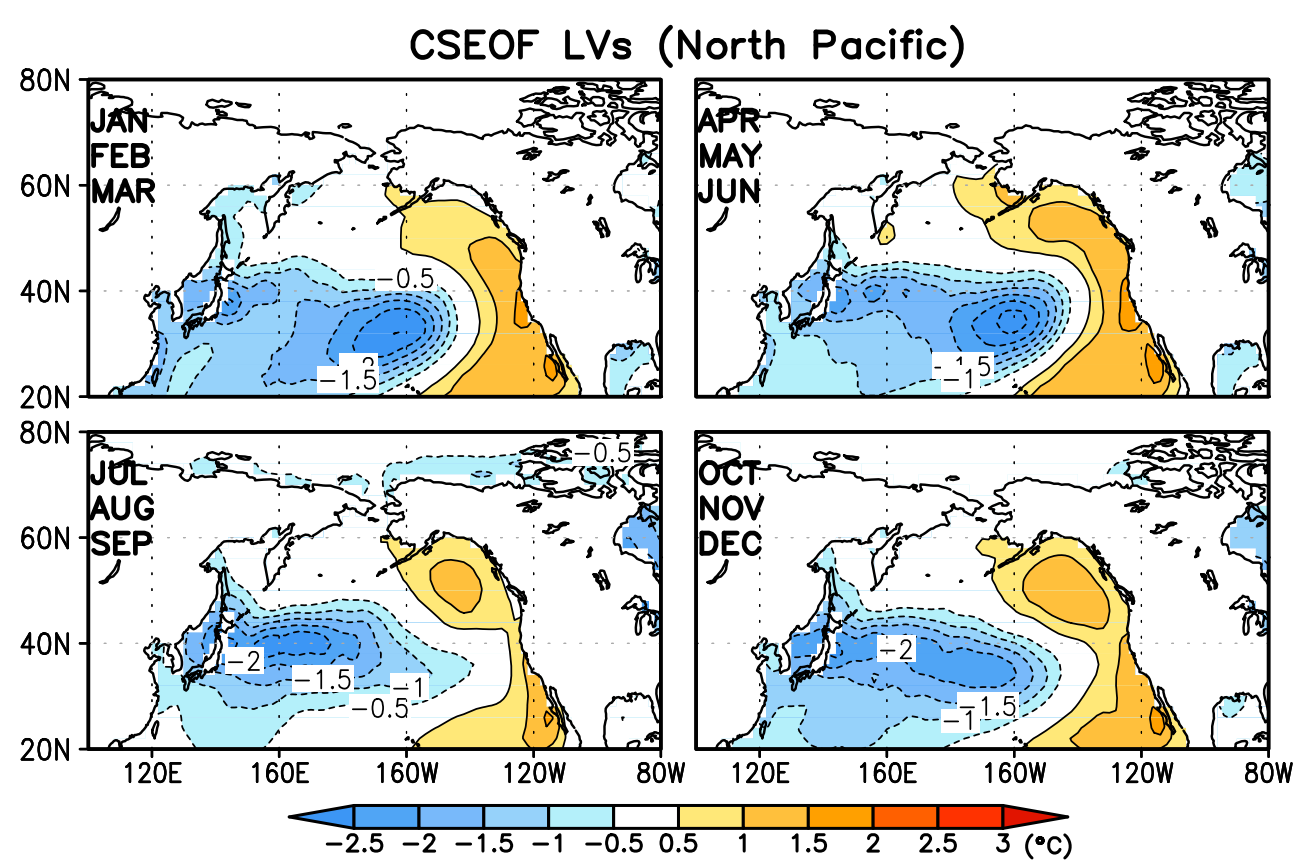

Fig. 3 The first CSEOF loading vectors of the 31-year (1980-2010) monthly SSTA $\left({ }^{\circ} \mathrm{C}\right)$ in the North Pacific $\left(100^{\circ} \mathrm{E}-80^{\circ} \mathrm{W}, 20^{\circ}-80^{\circ} \mathrm{N}\right)$. The contour interval is $0.5^{\circ} \mathrm{C}$. Each spatial pattern represents the seasonal (3-month) average of the loading vectors

\section{CSEOF LVs (Bering/Chukchi,1999-2010)}
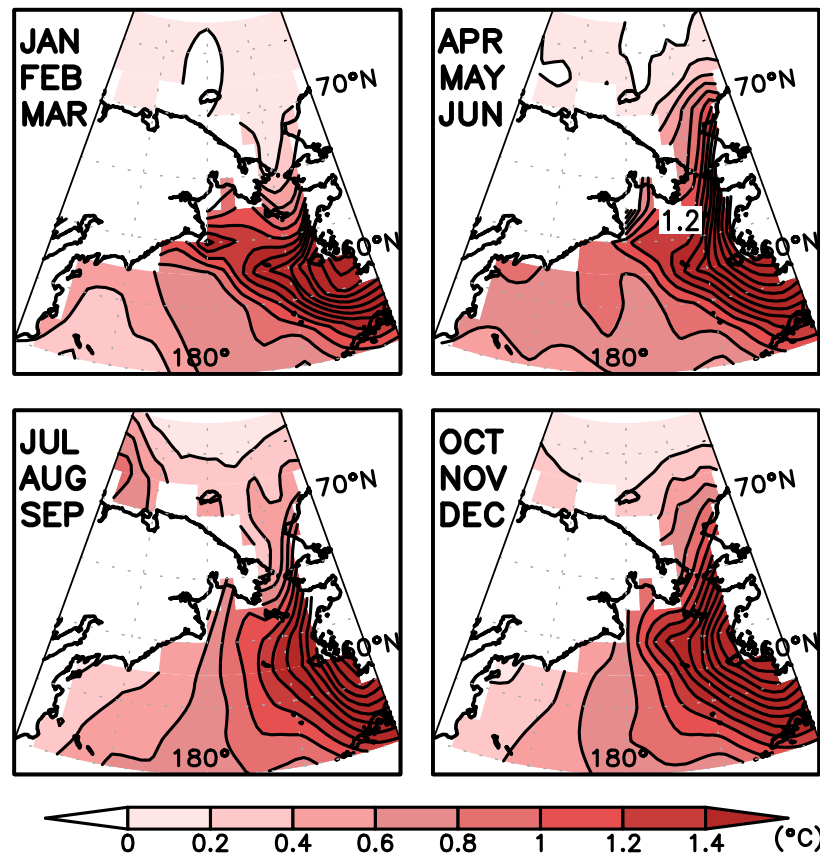

Fig. 4 Seasonal (3-month) averages of the first CSEOF loading vector of the SSTA $\left({ }^{\circ} \mathrm{C}\right)$ in the Bering and Chukchi Seas $\left(160^{\circ} \mathrm{E}-\right.$ $160^{\circ} \mathrm{W}, 54^{\circ}-76^{\circ} \mathrm{N}$ ) for $1999-2010$. The contour interval is $0.2^{\circ} \mathrm{C}$

almost the same variability as that of the entire period in Fig. $2(r=0.95)$. It should be pointed out that SSTA generally peaks in summer from July to September.
Variation of sea ice concentration is a crucial component of the physical environment in the Bering and Chukchi Seas that interacts with the ocean and the atmosphere primarily by altering the absorption of solar radiation and surface heat flux. Therefore, regression analysis was performed to identify the SIC and the net surface energy flux patterns over the Bering and Chukchi Seas, corresponding to the SSTA patterns in Fig. 4. Figure 5 displays the regressed spatial patterns of the SIC anomaly (contour) and the net surface flux anomaly (shading) onto the first CSEOF mode of the Bering and Chukchi SSTA in 1999-2010. The $R^{2}$ values, which measure the goodness of regression fit, are higher than 0.95 for both the SIC and the net surface flux. Thus, the amplitude time series of the regressed patterns in Fig. 5 are essentially identical to that of the Bering and Chukchi SSTA in Fig. 4. The $R^{2}$ values, by contrast, are approximately 0.6 for the period of 1980-1998. These relatively small $R^{2}$ values indicate that a strong physical connection between the SSTA and the SIC or the net surface flux was not established in the Bering Sea in 1980-1998; thus, the following discussion focuses on the period from 1999 to 2010. The regressed SIC anomalies in Fig. 5 are generally negative throughout the year, suggesting a natural outcome that warmer SST results in smaller SIC. The Bering Sea is subjected to a large seasonal variation of insolation, which results in the pronounced seasonality of the sea ice cover. Beginning roughly in November, sea ice prevails in the northern Bering Sea and SIC reaches its maximum in 


\section{Regressed Field of Net surface Heat Flux (Shading) \& Sea lce Concentration (Contour)}
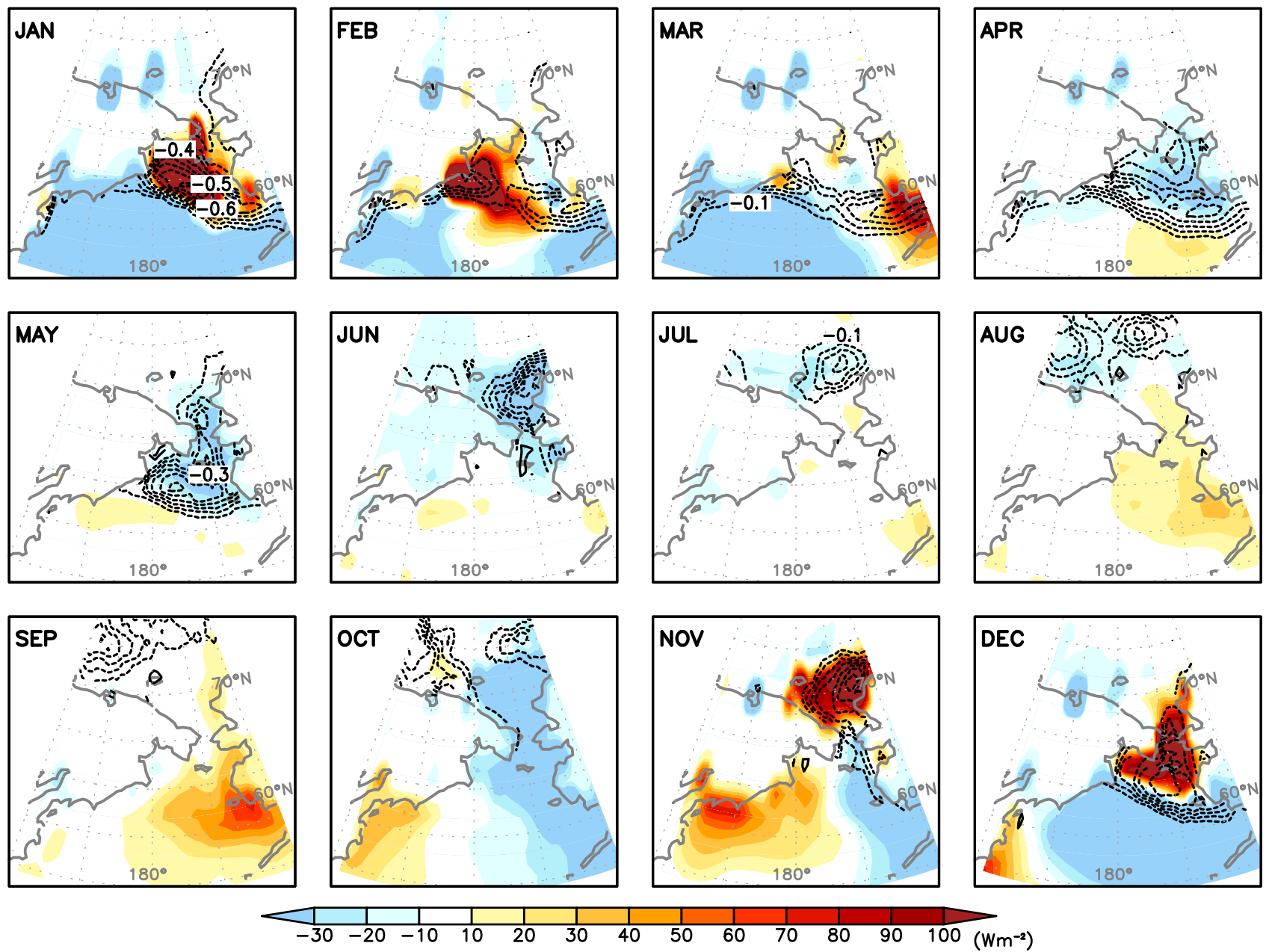

Fig. 5 The regressed patterns of SIC anomalies (contour) and net surface energy flux anomalies (shading, $\mathrm{W} \mathrm{m}^{-2}$ ) onto the first CSEOF mode of the Bering and Chukchi Seas SSTA during 1999-2010. The contour interval for SIC is 0.1 with negative values dashed, and the zero contour is omitted. The energy flux anomaly is defined as positive in the upward direction
March or early April. From spring to summer, with increased solar radiation and temperature, the Bering Sea is in virtually ice-free condition. This seasonal sea ice change is the largest of any of the Arctic or subarctic regions. As expected, the regressed pattern of SIC reveals a strong seasonal evolution (Fig. 5). Negative SIC anomaly persists in the Bering Sea from December to May, while the negative region moves to the Chukchi Sea from June to November.

The superimposed shading in Fig. 5 represents the regressed net surface energy flux anomaly. A positive value defines an upward flux from the ocean to the atmosphere. As illustrated in Fig. 5, there is a strong spatial coherence between SIC and net surface flux anomalies, although the sign of correlation is reversed between warm (AprilAugust) and cold (November-March) seasons. Negative SIC anomaly generally coincides with negative flux anomaly in the warm season, but with positive flux anomaly in the cold season. The magnitude of the upward flux in the cold season is much larger than the downward flux in the warm season.

In the Arctic and subarctic region including the Bering and Chukchi Seas, two of the most important sea ice related processes that affect air-sea interaction are the icealbedo feedback and the oceanic heat transport (Screen and Simmonds 2010a, b). Melting sea ice exposes the open water that effectively absorbs incoming sunlight than the sea ice, which leads to an increase in surface air temperature; this so-called ice-albedo feedback can only be active in summer with sufficient insolation (Deser et al. 2000). Thus, the downward heat flux anomaly in the warm season in Fig. 5 may be attributed to the increased absorption of solar radiation due to ice-albedo feedback. The flux patterns in the warm season are also consistent with the Arctic 
Regressed Field of $1000 \mathrm{hPa}$ AIRT
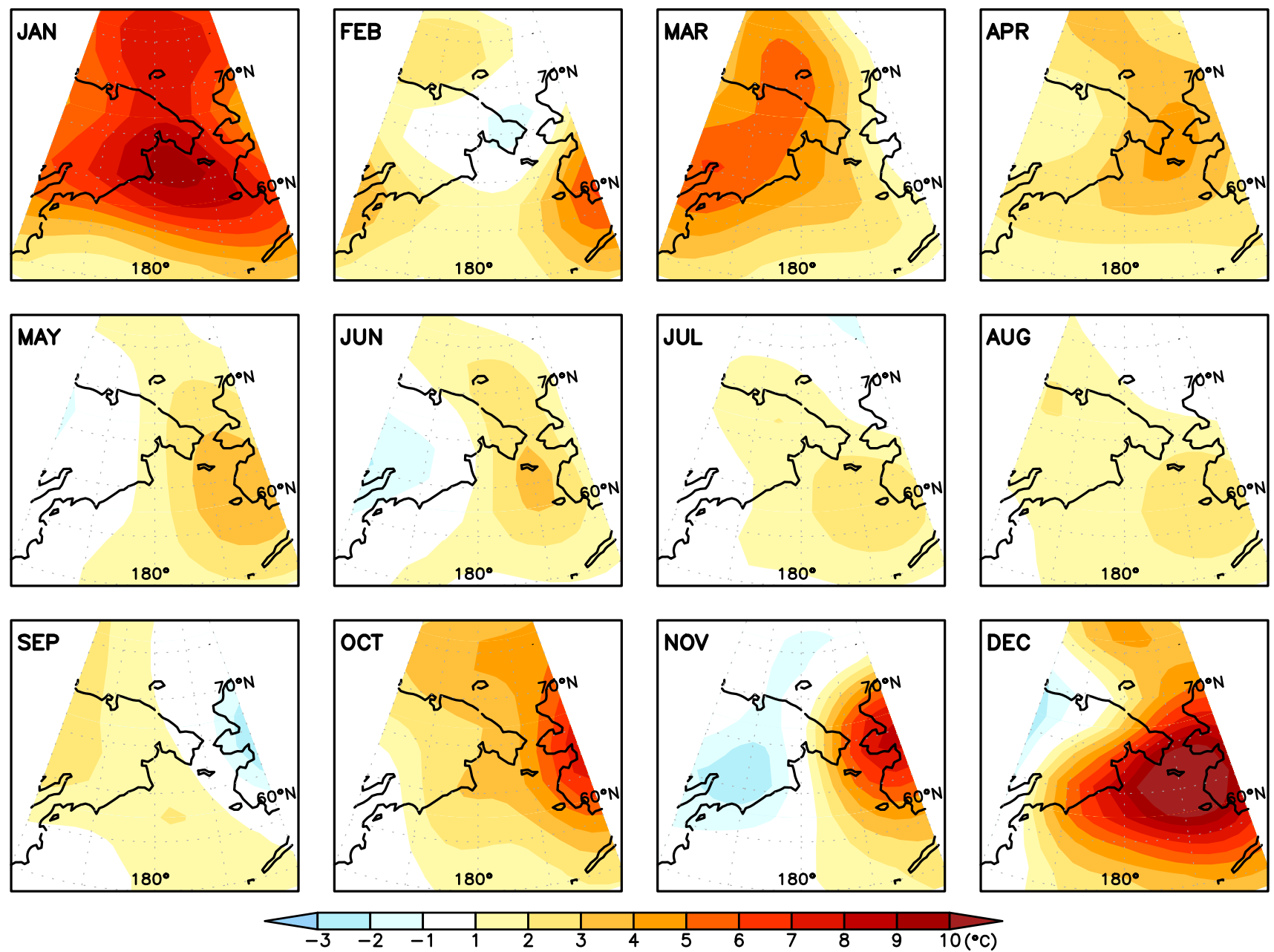

Fig. 6 The regressed patterns of the 1,000-hPa air temperature anomalies $\left({ }^{\circ} \mathrm{C}\right)$ onto the first CSEOF mode of the Bering and Chukchi Seas SSTA during 1999-2010

Ocean being more efficient in absorbing atmospheric heat during summer (Screen and Simmonds 2010b).

In winter, on the other hand, the primary air-sea interaction mechanism is the oceanic heat transport, since the albedo effect is suppressed due to the low insolation (Screen and Simmonds 2010a, b). Screen and Simmonds (2010b) proposed two explanations for the relationship between SIC and net surface flux in winter season. As a direct response to reductions in winter sea ice cover, heat is released from the relatively warm ocean surface to the colder atmosphere above. As an indirect response, sea ice reduction in summer also facilitates increased heat transfer from the ocean to the atmosphere in winter; sea ice cover reduction in summer leads to heat storage in the ocean, which is released in winter. Indeed, Fig. 5 exhibits striking spatial coherence between the negative SIC and the upward flux anomalies in the cold season, which supports that melting sea ice facilitates increased oceanic heat loss. An implication is that sea ice plays a significant role in forcing the atmosphere above by regulating energy flux transfer.

Examining the near-surface air temperature adds further insight into the forcing process from the ocean to the atmosphere. Figure 6 shows the regression pattern of 1,000-hPa air temperature on the first CSEOF mode of the Bering and Chukchi Seas SSTA in 1999-2010. The largest air temperature anomaly occurs in the winter season, with warming generally coincides with the upward flux anomaly associated with the reduced sea ice cover. Although SSTA warming peaks in summer and the direct ice-albedo feedback is greatest in summer, surface air temperature warming is not so strong in summer (Fig. 6). Ocean heat loss in winter is by far a more important source of atmospheric warming. The result presented in this section is consistent with Screen and Simmonds (2010b), who identified the fall-winter energy loss from the Arctic Ocean and the associated air temperature amplification. 
Fig. 7 The patterns of 1,000$\mathrm{hPa}$ geopotential height (contour, $\mathrm{m}$ ), wind (vector, $\mathrm{m} \mathrm{s}^{-1}$ ) and the air temperature (shading, ${ }^{\circ} \mathrm{C}$ ) anomalies over the North Pacific $\left(100^{\circ} \mathrm{E}-80^{\circ} \mathrm{W}\right.$, $20^{\circ}-85^{\circ} \mathrm{N}$ ) for a December, b January, c February, and d March regressed onto the first CSEOF mode of the Bering Sea SSTA for 1999-2010 (left panel), and the vertical sections of the regressed geopotential height (contour, $\mathrm{m}$ ), air temperature (shading, ${ }^{\circ} \mathrm{C}$ ) anomalies averaged over the longitude band of $180^{\circ}-140^{\circ} \mathrm{W}$ (right panel). The contour interval for geopotential height is $20 \mathrm{~m}$ for both panels
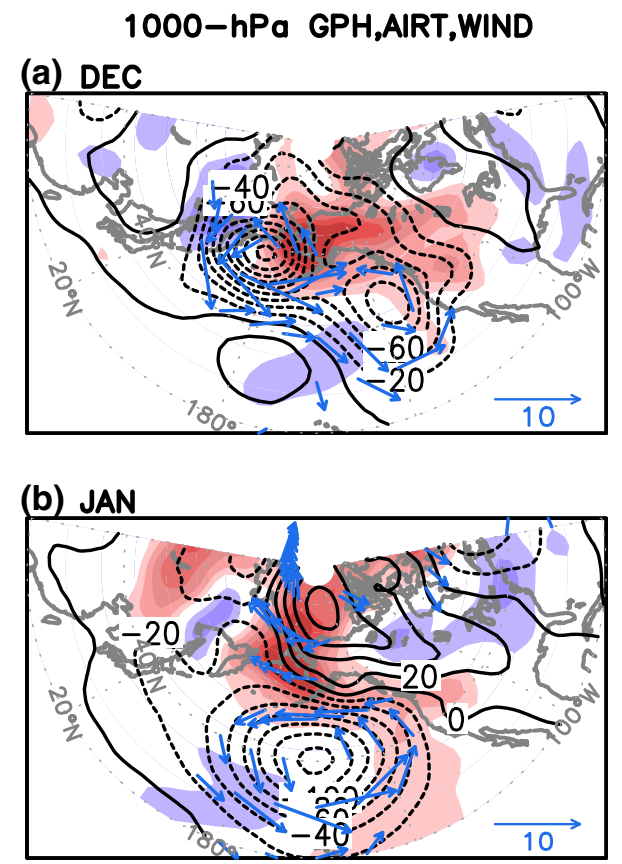

\section{(c) FEB}

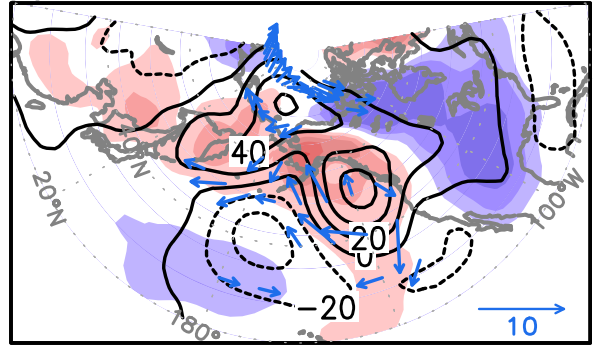

(d) MAR

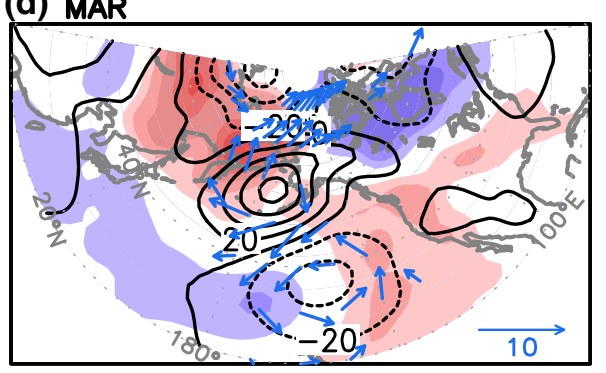

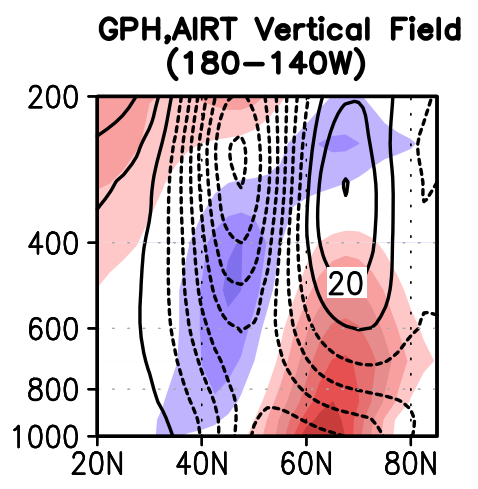
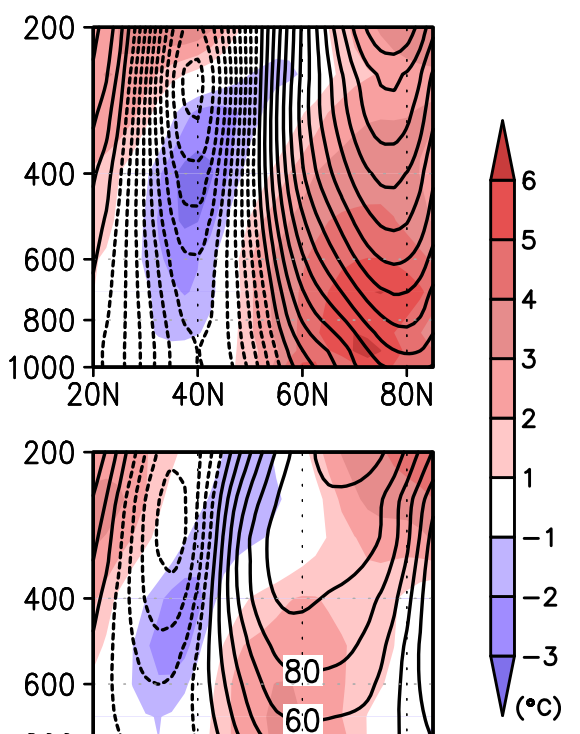

\section{North Pacific atmospheric circulation}

\subsection{Regression analysis}

Atmospheric response to the recent thermal variability in the Bering Sea does not seem confined to the Bering Sea region, but also appear in the North Pacific. Henceforth, large-scale atmospheric circulation over the North Pacific is investigated in association with the recent thermal state change in the Bering Sea (Fig. 4). Figure 7 illustrates the regressed 1,000-hPa geopotential height (contour), wind (vector), and air temperature (shading) anomalies over the North Pacific region $\left(100^{\circ} \mathrm{E}-80^{\circ} \mathrm{W}, 20^{\circ}-85^{\circ} \mathrm{N}\right)$ onto the leading CSEOF mode of SSTA over the Bering and Chukchi Seas in 1999-2010; the $R^{2}$ values are 0.94, 0.95 and 0.92 for geopotential height, wind, and air temperature, respectively. The winter spatial patterns are presented in Fig. 7, since upward flux is significant in winter (Fig. 5). Although the atmospheric circulation patterns in Fig. 7 are comparable to each other, considerable monthly variation is seen in the pattern and amplitude. The 1,000-hPa geopotential height in December exhibits negative pressure 
anomalies over the Bering Sea and the surrounding area (Fig. 7a). In January, positive pressure anomalies dominate to the north of $60^{\circ} \mathrm{N}$ and the negative pressure anomalies shift southward, constituting a north-south dipole structure. This dipole pattern resembles the NPO pattern, which is the second leading mode of North Pacific sea level pressure (Linkin and Nigam 2008; Rogers 1981). Similar dipole patterns are found in February and March with weaker amplitudes. In particular, a substantial fraction of the Bering Sea region is covered by positive pressure anomalies in January-March.

The accompanying air temperature anomalies, shown as shading in Fig. 7, display warm air temperature anomalies to the north of $50^{\circ} \mathrm{N}$ with centers in the Bering Sea region. The vertical sections of temperature (shading) and geopotential height anomalies (contour) averaged over the Bering Sea region $\left(180^{\circ}-140^{\circ} \mathrm{W}\right)$ are shown in Fig. 7. Warming over the Bering Sea is not confined to the lower troposphere but is also evident in the upper troposphere. In December, positive temperature anomalies over the Bering Sea region reach approximately $400 \mathrm{hPa}$ and a baroclinic geopotential height structure with a nodal point near $600 \mathrm{hPa}$ is observed. The linear model result of Hoskins and Karoly (1981) indicates that this baroclinic response is forced by diabatic heating in the lower troposphere associated with surface heat flux deriving from the imposed boundary forcing. In January, on the other hand, an equivalent barotropic structure is observed. The warm air temperature anomaly over the Bering Sea reaches a mature state in January, exhibiting amplification and expansion to near the tropopause. As a result, the thickness of the atmospheric layer increases further, and the atmospheric circulation adjusts to the equivalent barotropic structure. The adjustment process from an initial baroclinic structure to an equivalent barotropic one was substantiated in atmospheric general circulation models (Peng et al. 2003; Deser et al. 2007). The barotropic dipole structure in January is maintained throughout winter, although the anomaly center varies in location and amplitude. The meridional dipole structure is roughly characterized as an NPO-like pattern. Although the NPO pattern is conventionally known as an intrinsic mode of variability (e.g., Rogers 1981), an NPO-like pattern seems to appear also as a result of an atmospheric response to the recent thermal forcing in the Bering Sea.

\subsection{Comparison with the CAM3 model simulation}

In order to confirm that the recent thermal condition in the Bering Sea can produce the meridional dipole pattern (i.e., NPO-like response) in winter, two sets of experiments were carried out using the CAM3 model-Clim_Run and SIC_Run. In the Clim_Run experiment, the monthly SST and SIC climatology data from the HadISST dataset for 1980-1998 are used to force CAM3. The SIC_Run experiment is the same as Clim_Run, except over the region of significant sea-ice reduction for 1999-2010; the monthly SST and SIC climatology data for 1999-2010 are used where SIC is reduced by $10 \%$ or more compared to 1980-1998. For each set of experiments, the model is integrated for 55 years, and the mean values over the last 50 years are analyzed to exclude the spin-up effect. Assuming that each year is statistically independent, the 50 -year mean is equivalent to an ensemble mean of 50 members. The seasonal (3-month) averages of the differences (SIC_Run minus Clim_Run) in the SST (shading) and SIC (contour) boundary conditions are illustrated in Fig. 8. SIC has declined more than $10 \%$ over the Arctic Ocean in the recent decade (1999-2010) compared to the previous period of 1980-1998. Such a change has already been pointed out in previous studies (Comiso et al. 2008; Maslanik et al. 2007; Stroeve et al. 2007). The Bering and Chukchi Sea ice has also declined except for the summer season (July-September); the sea ice in this region retreats completely in summer. By comparing SIC_Run and Clim_Run experiments, therefore, an atmospheric response to the recent change in the SST and SIC over the Arctic Ocean can be identified. Of particular interest is the atmospheric response over the North Pacific in the winter season. Since the dipole structure is most pronounced in January and February in the regression patterns (Fig. 7), analysis for model result will also focus on January and February.

Figure 9a shows the difference in the January-February mean of $1,000-\mathrm{hPa}$ geopotential height (contour), wind (vector), and air temperature (shading) between the two simulations (SIC_Run minus Clim_Run) over the North Pacific region $\left(100^{\circ} \mathrm{E}-80^{\circ} \mathrm{W}, 20^{\circ}-85^{\circ} \mathrm{N}\right)$. The vertical cross-sections of the difference in geopotential height (contour) and air temperature (shading) averaged over the longitude band of $180^{\circ}-140^{\circ} \mathrm{W}$ are illustrated in Fig. $9 \mathrm{~b}$. The corresponding regression patterns in Fig. 7 are reproduced in the lower panel of Fig. 9. It is evident that CAM3 captures positive pressure anomaly over the Bering and Chukchi Seas and negative pressure anomaly south of $50^{\circ} \mathrm{N}$ in response to the warmer SST and reduced SIC. Spatial correlation of the 1,000-hPa geopotential height anomaly patterns (Fig. 9a, c) is 0.75 , supporting that the atmospheric response in winter over the North Pacific consists of a meridional dipole structure, which resembles the NPO pattern. In addition, the vertical structure of the response (Fig. 9b) exhibits a striking similarity with the regression result (Fig. 9d). They share common features of an equivalent barotropic high over $60^{\circ}-80^{\circ} \mathrm{N}$ in association with warming in the entire troposphere and a barotropic low over $30^{\circ}-50^{\circ} \mathrm{N}$, exhibiting a north-south dipole 


\section{CAM3 Model Boundary condition (SIC_Run-Clim_Run, seasonal mean)}
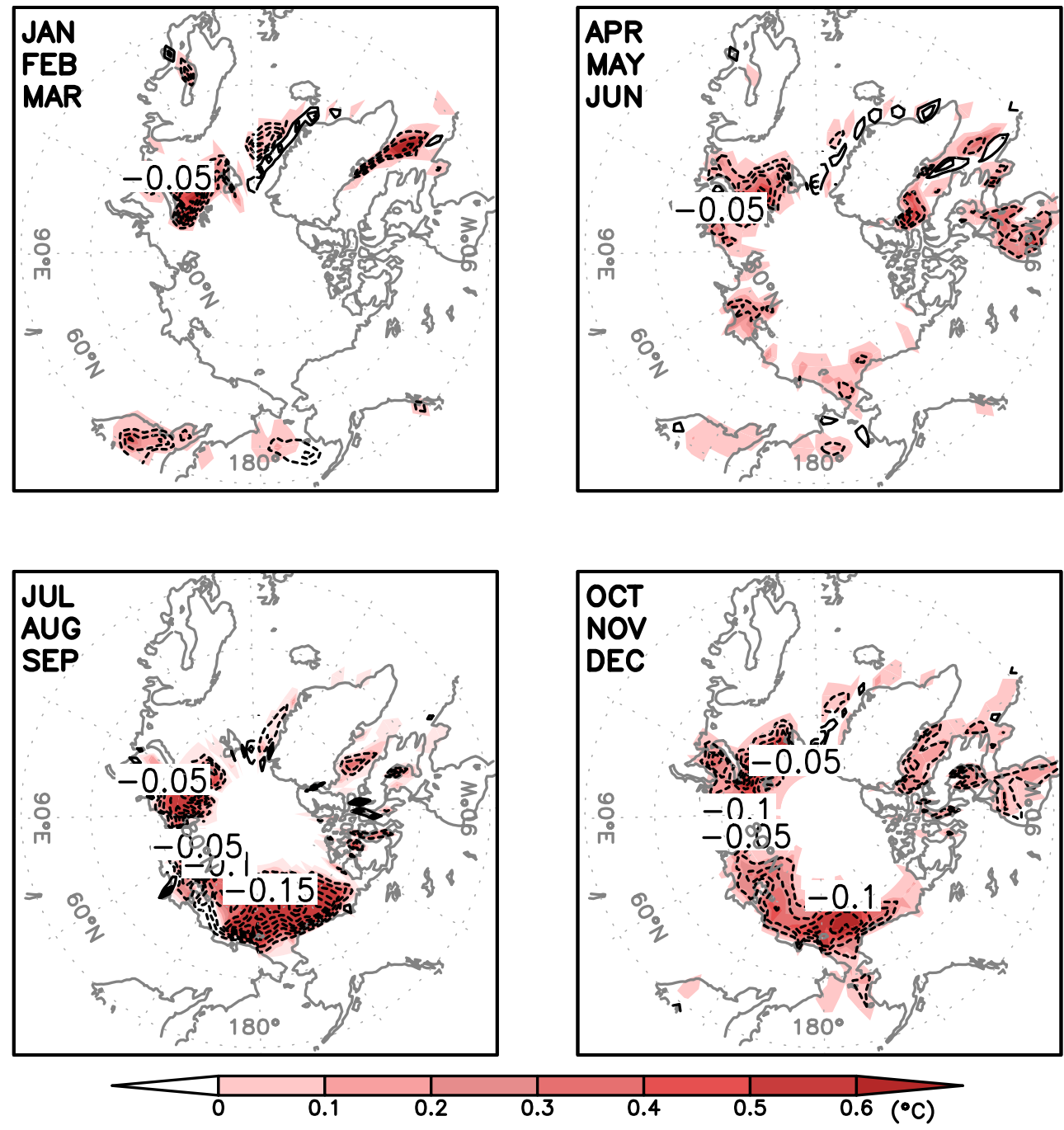

Fig. 8 The difference (SIC_Run minus Clim_Run) in the SST (shading, ${ }^{\circ} \mathrm{C}$ ) and SIC (contour) boundary conditions. Each spatial pattern represents the seasonal (3-month) average of the difference of the boundary conditions. The contour interval for SIC is 0.05

structure across approximately $50^{\circ} \mathrm{N}$. This experimental result supports that the NPO-like atmospheric response may have been derived from the recent warming of the Bering and Chukchi Seas.

\section{Covariability of Bering Sea SST and Pacific large-scale circulation}

Based on CSEOF analysis and the CAM3 model simulation, it is identified that the warming and sea ice reduction in the Bering and Chukchi Seas during the last decade are closely related to the atmospheric NPO-like pattern. The NPO pattern, a key atmospheric mode in the Pacific basin, is well known for its strong influence on weather patterns over Eurasia and North America, and in particular storm tracks, temperatures, and precipitation (Seager et al. 2005; Linkin and Nigam 2008). The NPO pattern, of course, exerts a strong influence over the Pacific basin; Di Lorenzo et al. (2008) found that the NPO serves as the atmospheric forcing pattern for the oceanic NPGO pattern. Previous studies also emphasized that the regional Bering Sea variability is closely related to the state of the entire Pacific climate system (Niebauer 1988; Minobe 2002).

Figure 10 displays the regressed spatial patterns of SSTA and 1,000-hPa geopotential height anomalies over the tropical and North Pacific $\left(100^{\circ} \mathrm{E}-80^{\circ} \mathrm{W}, 10^{\circ} \mathrm{S}-70^{\circ} \mathrm{N}\right)$. The $R^{2}$ values are 0.96 and 0.94 for the SSTA and the 


\section{CAM3 Model Result (SIC_Run-Clim_Run, JAN-FEB)}

(a) $1000 \mathrm{hPa}$ GPH,AIRT,WIND

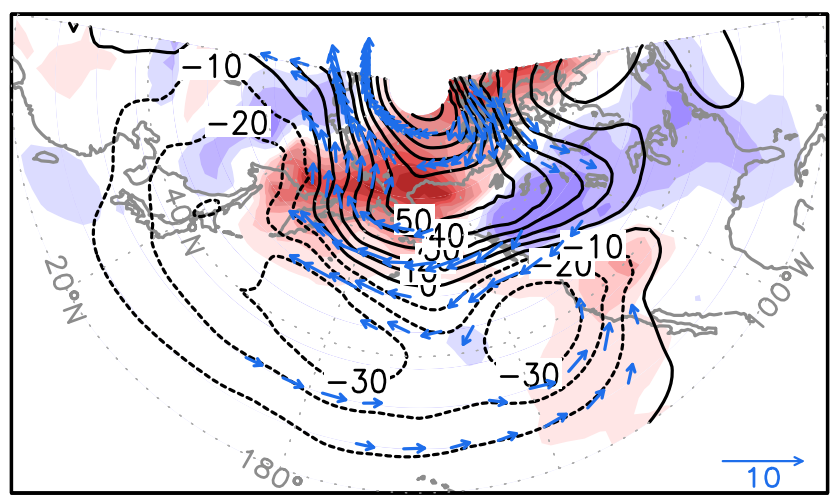

(b) GPH,AIRT vertical field

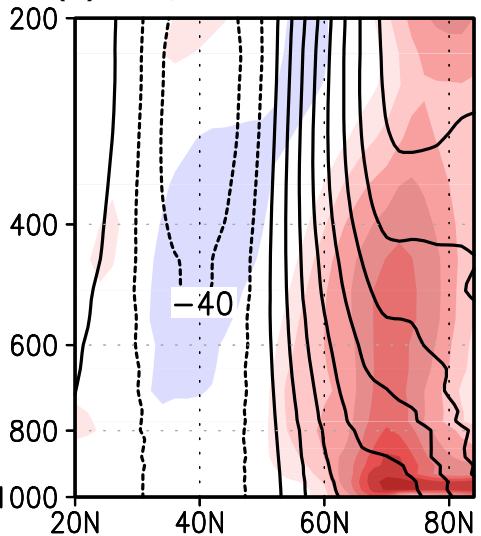

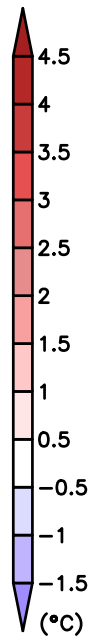

Regression Field (JAN-FEB)

(c) $1000 \mathrm{hPa}$ GPH,AIRT,WIND

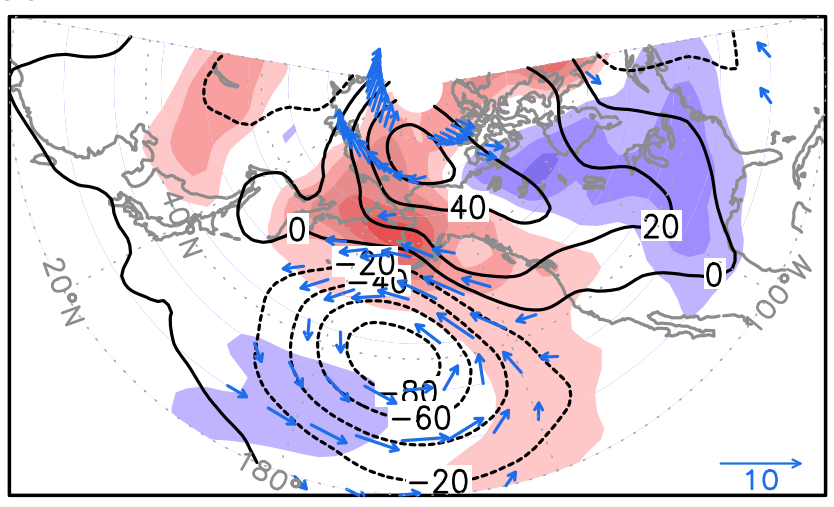

(d) GPH,AIRT vertical field

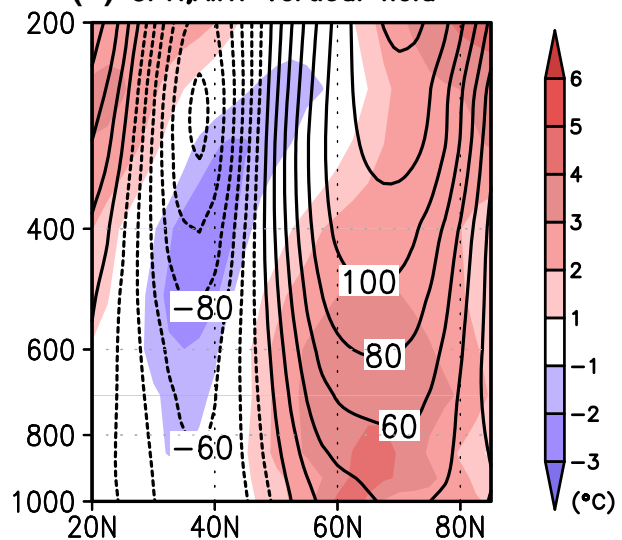

Fig. 9 a The SIC_Run minus Clim_Run difference of the January and February mean 1,000-hPa geopotential height (contour, $\mathrm{m}$ ), wind (vector, $\mathrm{m} \mathrm{s}^{-1}$ ) and air temperature (shading, ${ }^{\circ} \mathrm{C}$ ) anomalies over the North Pacific $\left(100^{\circ} \mathrm{E}-80^{\circ} \mathrm{W}, 20^{\circ}-85^{\circ} \mathrm{N}\right)$. The contour interval for geopotential height is $10 \mathrm{~m}$. b The difference (SIC_Run minus Clim_Run) of the vertical cross-section of the geopotential height (contour, m), air temperature (shading, ${ }^{\circ} \mathrm{C}$ ) averaged over the longitude band $180^{\circ}-140^{\circ} \mathrm{W}$. Plotted here are the differences divided by the standard deviation of the first CSEOF PC time series of the Bering Sea SSTA. c The January-February mean regressed patterns of 1,000-hPa geopotential height, wind and air temperature anomalies and $\mathbf{d}$ the vertical sections of the geopotential height and air temperature. The contour interval for geopotential height is $20 \mathrm{~m}$ geopotential height anomaly, respectively. To further examine the mechanistic details, the regressed patterns of anomalous net surface energy flux and wind at 1,000 hPa were also investigated and are shown in Fig. 11; the $R^{2}$ values are 0.90 and 0.92 , respectively. The significant correlations imply that the recent SST variability in the Bering and Chukchi Seas and the spatial patterns of the Pacific basin depicted in Figs. 10 and 11 share essentially the same amplitude variation. According to the similarity of the evolution patterns, seasonal mean (3-month) patterns from January to September are presented in Figs. 10 and 11.

As noted above, the North Pacific atmospheric response to the recent warming in the Bering and Chukchi Seas during winter is the NPO-like pattern (Fig. 10a). The corresponding SSTA over the North Pacific bears a strong resemblance to that of the NPGO pattern; the positive SSTA in the eastern North Pacific extends across the Pacific to the western Bering Sea and the Sea of Okhotsk resulting in meridional gradient of SSTA along approximately $40^{\circ} \mathrm{N}$. The physical relationship between the NPO and the NPGO SSTA pattern presented in Fig. 10a can be explained by the air-sea interaction. As illustrated in Fig. 7b, the southerly wind anomaly over the eastern North Pacific advects warm and moist air, leading to warm air temperature anomaly in this region. Note that this warm air temperature anomaly extended southward in the eastern North Pacific does not yet appear in December, since the NPO pattern is not fully established (Fig. 7a). The 


\section{Regressed SST (shading) \& $1000 \mathrm{hPa} \mathrm{GPH}$}

(a) JAN,FEB, MAR
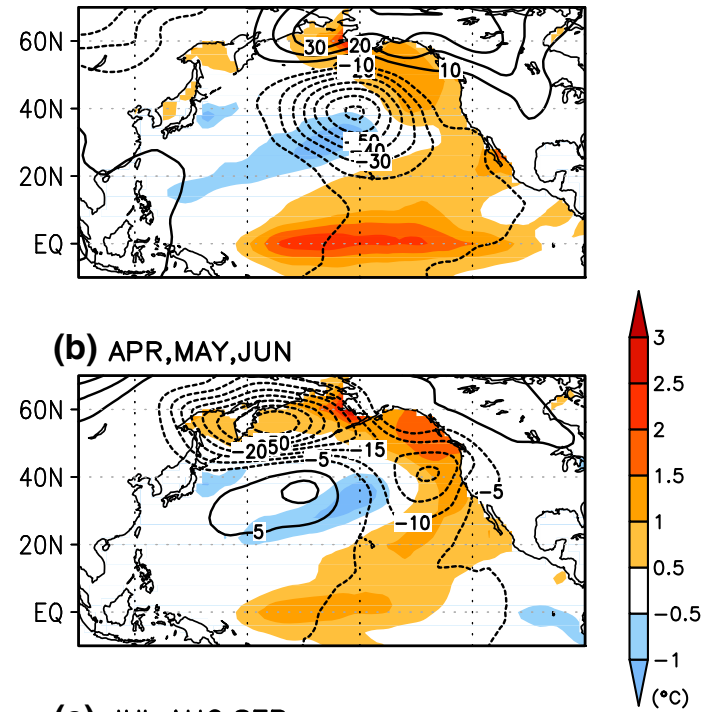

(c) JUL,AUG,SEP

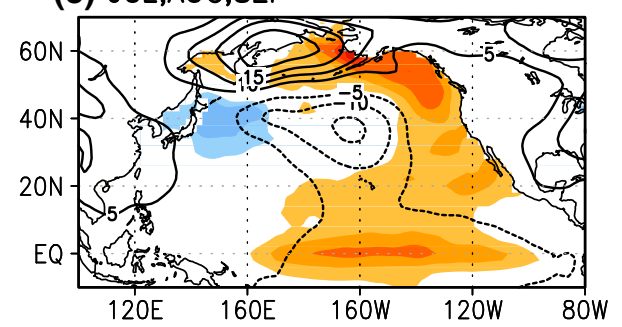

Fig. 10 The regressed patterns of the 1,000-hPa geopotential height anomaly (contour, m) and SST anomaly (shading, ${ }^{\circ} \mathrm{C}$ ) corresponding to the first CSEOF loading vector of the Bering and Chukchi SSTA during the period 1999-2010. Seasonal (3-month) average patterns are represented. Note that the contour interval is $10 \mathrm{~m}$ for panel $\mathbf{a}$, and $5 \mathrm{~m}$ for panel $\mathbf{b}$ and $\mathbf{c}$

associated net surface flux anomaly in the eastern North Pacific exhibits downward flux (Fig. 11a), which subsequently produces a positive SSTA (Fig. 10a). The northerly wind, in contrast, advects cold and dry air into the central North Pacific, resulting in an upward heat flux anomaly and cold SSTA. Although the air-sea interaction appears to be inactive in spring and summer (Fig. 11b, c), positive SSTA is observed over the northeastern Pacific for several seasons (Fig. 10b, c).

Another important feature in Figs. 10 and 11 is that the oceanic and atmospheric variations in the North Pacific extend to the subtropical and tropical Pacific. Figure 10 displays the positive SSTA extending southwestward from Baja California to the tropical central Pacific. Also, the negative geopotential height extends across much of the Pacific basin from the mid-latitudes to the tropics. This North Pacific-tropical Pacific connection is evident not only in winter but also in spring and summer. The accompanying tropical Pacific SSTA features warming over the tropical central Pacific, that is, CP El Niño

\section{Regressed surface heat flux (shading) \& $1000 \mathrm{hPa}$ Wind}

(a) JAN,FEB,MAR

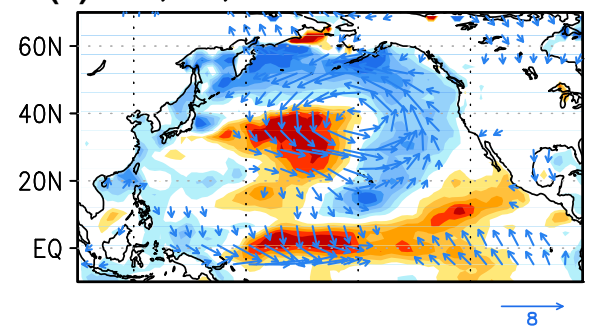

(b) APR, MAY,JUN
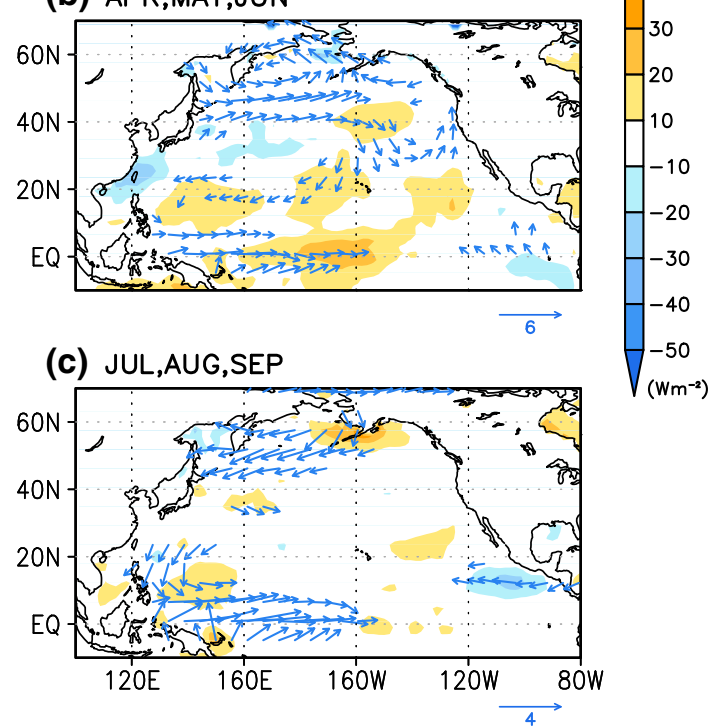

Fig. 11 The regressed patterns of the 1,000-hPa wind anomaly (vector, $\mathrm{m} \mathrm{s}^{-1}$ ) and net surface energy flux anomaly (shading, $\mathrm{W} \mathrm{m}^{-2}$ ) corresponding to the first CSEOF loading vector of the Bering and Chukchi SSTA during the period 1999-2010. The seasonal (3-month) average spatial patterns are represented. Note that vector scale is different for each panel

(Fig. 10). The atmospheric flow over the tropical Pacific displays westerly anomaly extending from the equatorial western to central Pacific and easterly anomaly over the eastern Pacific (Fig. 11). Di Lorenzo et al. (2010) suggested that the CP El Niño is tightly linked to the NPGO pattern via atmospheric teleconnection of the NPO. More recent studies have noted that the mid-latitude NPO forcing is particularly influential in the initial establishment of SSTA in the tropical central Pacific for CP El Niño events (Furtado et al. 2011; Kim et al. 2012; Yu and Kim 2011). This covariability of the NPO, NPGO and CP El Niño is clearly demonstrated in the regression patterns over the Pacific basin in connection with the warming of the Bering and Chukchi Seas during 1999-2010 (Figs. 10, 11). Indeed, the CP El Niño events in the recent decade, such as 2002/2003 and 2004/2005, concur with the positive SSTA in the Bering and Chukchi Seas region (see the PC time series in Fig. 2). Although data analysis in this study is 
inconclusive in regard to the cause-effect relationship among the Bering and Chukchi Seas warming, the NPO and the CP El Niño, their physical connectivity has become clearer and stronger during the recent decade.

\section{Discussion and conclusion}

The climate in the Bering Sea exhibits interdecadal variation, with distinct anomalous conditions occurred in 1997 and 1998. After unusual physical conditions during 1997-1998, recent (1999-2010) climate variability in the Bering Sea exhibits a closer connectivity with the North Pacific. CSEOF analysis reveals that the recent warming in the Bering Sea and the resultant reduction in SIC involves stronger oceanic heat loss in winter. In accordance with the increased heat transfer from the Bering Sea to the atmosphere, atmospheric circulation over the North Pacific exhibits an NPO-like pattern in winter (January-March). An experiment with the CAM3 model confirms and supports this connection between the Bering Sea and the North Pacific.

In the previous period (1980-1998), on the other hand, SST, sea ice, and energy flux in the Bering and Chukchi Seas seem to exhibit a weaker physical connectivity in comparison with the recent decade. Consequently, a strong physical connection between the climate variability in the Bering and Chukchi Seas and that of the North Pacific cannot be established in the previous period. Note that the $R^{2}$ value of the $1,000-\mathrm{hPa}$ geopotential height regressed onto the first CSEOF of the Bering Sea SSTA is merely 0.3 in the earlier period, indicating that there is no significant physical relationship (or covariability) between the two regions. The atmospheric response in the North Pacific to the increased energy flux in the Bering and Chukchi Seas, that is, the NPO-like pattern, is a peculiar aspect of the recent decade (1999-2010).

The NPO pattern exerts strong influence over the North Pacific, serving as the atmospheric forcing for the oceanic NPGO pattern (Di Lorenzo et al. 2010). Furthermore, several recent studies argued that the initial establishment of SST anomalies in the tropical central Pacific is intimately tied to mid-latitude atmospheric variability, that is, the NPO pattern (Furtado et al. 2011; Kim et al. 2012; Yu and Kim 2011). The important links between the CP El Niño, the NPO and the NPGO constitute a prominent lowfrequency variability in the Pacific basin in the recent decade. Indeed, several recent studies suggested that primary decadal-scale changes in the state of the North Pacific and the tropical Pacific occurred in the late 1990s (Bond et al. 2003; Yeo et al. 2012; Xiang et al. 2012). The CP El Niño has occurred more frequently (Kug et al. 2009; Lee and McPhaden 2010; Yeh et al. 2009) and the NPGO amplitude has been generally larger than the PDO amplitude (Bond et al. 2003; Di Lorenzo et al. 2008) since the late 1990s.

It is interesting to note that the prominent patterns of Pacific variability (i.e., NPGO and CP El Niño) in recent years appear as the regression patterns of the first CSEOF mode of the Bering Sea SSTA for 1999-2010. This reflects stronger connection of the climate variability in the Bering Sea and the prominent climate modes over the Pacific basin in the recent decade. Even though large-scale climate variability in the Pacific has been known as a dominant source of Bering Sea climate variability, the EP El Niño and the PDO do not actually account for much of the interannual variability of the Bering Sea climate; EP El Niño accounts for $\sim 7 \%$ of the sea ice variance in the Bering Sea (Niebauer 1988) and the variance of Bering Sea SSTA explained by the PDO is $10 \%$ (Minobe 2002). In contrast, Bering Sea variability in the recent decade is significantly $\left(R^{2}>0.9\right)$ connected to the NPGO-like pattern and the CP El Niño. This implies that the Bering Sea in the recent decade serves as an integral component of a prominent low-frequency variability in the Pacific along with the NPGO and the CP El Niño.

Considering the short analysis period, it is hard to identify the cause-effect relationship between variability in the Bering Sea, and that of the Pacific basin. Therefore, investigations based on model experiments are required to further explore the detailed mechanisms of this physical connection. Additional analysis of the global warming scenario datasets under the auspice of the Intergovernmental Panel on Climate Change (IPCC) Fifth Assessment Report (AR5) will provide better insight into the interaction between the Bering Sea and the Pacific under the global warming state.

Acknowledgments This research was supported by the project entitled "Ocean Climate Change: Analysis, Projections, Adaptation (OCCAPA)" funded by the Ministry of Land, Transport, and Maritime Affairs, Korea.

Open Access This article is distributed under the terms of the Creative Commons Attribution License which permits any use, distribution, and reproduction in any medium, provided the original author(s) and the source are credited.

\section{References}

Ashok K, Behera SK, Rao SA, Weng H, Yamagata T (2007) El Niño Modoki and its possible teleconnection. J Geophys Res 112(C11):C11007

Bond N, Overland J, Spillane M, Stabeno P (2003) Recent shifts in the state of the North Pacific. Geophys Res Lett 30(23):2183

Brodeur RD, Mills CE, Overland JE, Walters GE, Schumacher JD (1999) Evidence for a substantial increase in gelatinous zooplankton in the Bering Sea, with possible links to climate change. Fish Oceanogr 8(4):296-306 
Ceballos LI, Di Lorenzo E, Hoyos CD, Schneider N, Taguchi B (2009) North Pacific gyre oscillation synchronizes climate fluctuations in the eastern and western boundary systems. J Climate 22(19):5163-5174

Collins WD, Rasch PJ, Boville BA, Hack JJ, McCaa JR, Williamson DL, Briegleb BP, Bitz CM, Lin SJ, Zhang M (2006) The formulation and atmospheric simulation of the community atmosphere model version 3 (CAM3). J Climate 19(11):2144-2161

Comiso JC, Parkinson CL, Gersten R, Stock L (2008) Accelerated decline in the Arctic sea ice cover. Geophys Res Lett 35(1):L01703

Deser C, Walsh JE, Timlin MS (2000) Arctic sea ice variability in the context of recent atmospheric circulation trends. J Climate 13(3):617-633

Deser C, Tomas RA, Peng S (2007) The transient atmospheric circulation response to North Atlantic SST and sea ice anomalies. J Climate 20(18):4751-4767

Di Lorenzo E, Schneider N, Cobb K, Franks P, Chhak K, Miller A, McWilliams J, Bograd S, Arango H, Curchitser E (2008) North Pacific Gyre Oscillation links ocean climate and ecosystem change. Geophys Res Lett 35(8):L08607

Di Lorenzo E, Cobb K, Furtado J, Schneider N, Anderson B, Bracco A, Alexander M, Vimont D (2010) Central Pacific El Niño and decadal climate change in the North Pacific Ocean. Nat Geosci 3(11):762-765

Furtado JC, Di Lorenzo E, Anderson BT, Schneider N (2011) Linkages between the North Pacific Oscillation and central tropical Pacific SSTs at low frequencies. Clim Dyn. doi:10.1007/ s00382-011-1245-4

Grebmeier JM, Overland JE, Moore SE, Farley EV, Carmack EC, Cooper LW, Frey KE, Helle JH, McLaughlin FA, McNutt SL (2006) A major ecosystem shift in the northern Bering Sea. Science 311(5766):1461-1464

Hare SR, Mantua NJ (2000) Empirical evidence for North Pacific regime shifts in 1977 and 1989. Prog Oceanogr 47(2-4):103-145

Hoskins BJ, Karoly DJ (1981) The steady linear response of a spherical atmosphere to thermal and orographic forcing. J Atmos Sci 38(6):1179-1196

Hunt GL Jr, Baduini C, Brodeur R, Coyle K, Kachel N, Napp J, Salo S, Schumacher J, Stabeno P, Stockwell D (1999) The Bering Sea in 1998: the second consecutive year of extreme weather-forced anomalies. EOS Trans AGU 80(47):561-566

Hunt GL Jr, Stabeno P, Walters G, Sinclair E, Brodeur RD, Napp JM, Bond NA (2002) Climate change and control of the southeastern Bering Sea pelagic ecosystem. Deep Sea Res Part II 49(26):5821-5853. doi:10.1016/S0967-0645(02)00321-1

Kanamitsu M, Ebisuzaki W, Woollen J, Yang SK, Hnilo J, Fiorino M, Potter G (2002) Ncep-doe amip-ii reanalysis (r-2). Bull Am Met Soc 83(11):1631-1644

Kao HY, Yu JY (2009) Contrasting eastern-Pacific and central-Pacific types of ENSO. J Climate 22(3):615-632

Kim KY, North GR (1997) EOFs of harmonizable cyclostationary processes. J Atmos Sci 54(19):2416-2427

Kim KY, North GR, Huang J (1996) EOFs of one-dimensional cyclostationary time series: computations, examples, and stochastic modeling. J Atmos Sci 53(7):1007-1016

Kim ST, Yu JY, Kumar A, Wang H (2012) Examination of the two types of ENSO in the NCEP CFS model and its extratropical associations. Mon Wea Rev 140:1908-1923

Kruse GH (1998) Salmon run failures in 1997-1998: a link to anomalous ocean conditions? Alaska Fish Res Bull 5(1):55-63

Kug JS, Jin FF, An SI (2009) Two types of El Niño events: cold tongue El Niño and warm pool El Niño. J Climate 22(6):1499-1515
Lee T, McPhaden MJ (2010) Increasing intensity of El Niño in the central-equatorial Pacific. Geophys Res Lett 37(14):L14603

Linkin ME, Nigam S (2008) The north pacific oscillation-west Pacific teleconnection pattern: mature-phase structure and winter impacts. J Climate 21(9):1979-1997

Maslanik J, Fowler C, Stroeve J, Drobot S, Zwally J, Yi D, Emery W (2007) A younger, thinner Arctic ice cover: increased potential for rapid, extensive sea-ice loss. Geophys Res Lett 34(24):L24501

Minobe S (2002) Interannual to interdecadal changes in the Bering Sea and concurrent 1998/99 changes over the North Pacific. Prog Oceanogr 55(1-2):45-64

Napp JM, Hunt GL Jr (2001) Anomalous conditions in the southeastern Bering Sea 1997: linkages among climate, weather, ocean, and Biology. Fish Oceanogr 10(1):61-68

National Research Council (1996) The Bering Sea ecosystem. National Academy Press, Washington, DC

Niebauer H (1988) Effects of El Niño-Southern Oscillation and North Pacific weather patterns on interannual variability in the subarctic Bering Sea. J Geophys Res 93(C5):5051-5068

Overland JE, Stabeno PJ (2004) Is the climate of the Bering Sea warming and affecting the ecosystem. EOS Trans AGU 85(33):309-316

Overland JE, Adams JM, Bond NA (1999) Decadal variability of the Aleutian low and its relation to high-latitude circulation. J Climate 12(5):1542-1548

Overland JE, Wang M, Wood KR, Percival DB, Bond NA (2012) Recent Bering Sea warm and cold events in a 95-year contest. Deep Sea Res Part II 65-70:6-13

Peng S, Robinson WA, Li S (2003) Mechanisms for the NAO responses to the North Atlantic SST tripole. J Climate 16(12):1987-2004

Rayner N, Parker D, Horton E, Folland C, Alexander L, Rowell D, Kent E, Kaplan A (2003) Global analyses of sea surface temperature, sea ice, and night marine air temperature since the late nineteenth century. J Geophys Res 108(D14):4407

Rogers JC (1981) The North Pacific oscillation. J Climatol 1(1):39-57

Schumacher J, Bond N, Brodeur R, Livingston P, Napp J, Stabeno P (2003) Climate change in the southeastern Bering Sea and some consequences for biota. Large Marine Ecosyst World Trends Exploit Prot Res 17-40

Screen JA, Simmonds I (2010a) The central role of diminishing sea ice in recent Arctic temperature amplification. Nature 464(7293):1334-1337

Screen JA, Simmonds I (2010b) Increasing fall-winter energy loss from the Arctic Ocean and its role in Arctic temperature amplification. Geophys Res Lett 37(16):L16707

Seager R, Harnik N, Robinson W, Kushnir Y, Ting M, Huang HP, Velez J (2005) Mechanisms of ENSO-forcing of hemispherically symmetric precipitation variability. Q J Roy Meteor Soc 131(608): 1501-1527

Smith TM, Reynolds RW, Peterson TC, Lawrimore J (2008) Improvements to NOAA's historical merged land-ocean surface temperature analysis (1880-2006). J Climate 21(10): 2283-2296

Stabeno P, Bond N, Kachel N, Salo S, Schumacher J (2001) On the temporal variability of the physical environment over the southeastern Bering Sea. Fish Oceanogr 10(1):81-98

Stabeno P, Bond N, Salo S (2007) On the recent warming of the southeastern Bering Sea shelf. Deep Sea Res Part II 54(23-26):2599-2618

Stockwell DA, Whitledge TE, Zeeman SI, Coyle KO, Napp JM, Brodeur RD, Pinchuk AI, Hunt JRGL (2001) Anomalous conditions in the south-eastern Bering Sea, 1997: nutrients, phytoplankton and zooplankton. Fish Oceanogr 10(1):99-116 
Stroeve J, Holland MM, Meier W, Scambos T, Serreze M (2007) Arctic sea ice decline: faster than forecast. Geophys Res Lett 34(9):9501

Xiang B, Wang B, Li T (2012) A new paradigm for the predominance of standing Central Pacific Warming after the late 1990s. Clim Dyn. doi:10.1007/s00382-012-1427-8

Yeh SW, Kug JS, Dewitte B, Kwon MH, Kirtman BP, Jin FF (2009) El Niño in a changing climate. Nature 461(7263):511-514

Yeh SW, Kang YJ, Noh Y, Miller AJ (2011) The North Pacific climate transitions of the winters of $1976 / 77$ and 1988/89. J Climate 24:1170-1183
Yeo SR, Kim KY, Yeh SW, Kim WM (2012) Decadal changes in the relationship between the tropical Pacific and the North Pacific. J Geophys Res 117(D15):D15102

Yu JY, Kim ST (2011) Relationships between extratropical sea level pressure variations and the central Pacific and eastern Pacific types of ENSO. J Climate 24(3):708-720 